\title{
Front Matter: Volume 6819
}

, "Front Matter: Volume 6819," Proc. SPIE 6819, Security, Forensics, Steganography, and Watermarking of Multimedia Contents X, 681901 (24 March 2008); doi: 10.1117/12.793470

SPIE. Event: Electronic Imaging, 2008, San Jose, California, United States 


\title{
Security, Forensics, Steganography, and Watermarking of Multimedia Contents $X$
}

\author{
Edward J. Delp III \\ Ping Wah Wong \\ Jana Dittmann \\ Nasir D. Memon \\ Editors
}

28-30 January 2008

San Jose, California, USA

Sponsored and Published by

IS\&T-The Society for Imaging Science and Technology

SPIE 
The papers included in this volume were part of the technical conference cited on the cover and title page. Papers were selected and subject to review by the editors and conference program committee. Some conference presentations may not be available for publication. The papers published in these proceedings reflect the work and thoughts of the authors and are published herein as submitted. The publishers are not responsible for the validity of the information or for any outcomes resulting from reliance thereon.

Please use the following format to cite material from this book:

Author(s), "Title of Paper," in Security, Forensics, Steganography, and Watermarking of Multimedia Contents X, edited by Edward J. Delp III, Ping Wah Wong, Jana Dittmann, Nasir D. Memon, Proceedings of SPIE-IS\&T Electronic Imaging, SPIE Vol. 6819, Article CID Number (2008).

ISSN 0277-786X

ISBN 9780819469915

Copublished by

SPIE

P.O. Box 10, Bellingham, Washington $98227-0010$ USA

Telephone +1 3606763290 (Pacific Time) · Fax +1 3606471445

SPIE.org

and

IS\&T-The Society for Imaging Science and Technology

7003 Kilworth Lane, Springfield, Virginia, 22151 USA

Telephone +1 7036429090 (Eastern Time) · Fax +1 7036429094

imaging.org

Copyright @ 2008, Society of Photo-Optical Instrumentation Engineers and The Society for Imaging Science and Technology.

Copying of material in this book for internal or personal use, or for the internal or personal use of specific clients, beyond the fair use provisions granted by the U.S. Copyright Law is authorized by the publishers subject to payment of copying fees. The Transactional Reporting Service base fee for this volume is $\$ 18.00$ per article (or portion thereof), which should be paid directly to the Copyright Clearance Center (CCC), 222 Rosewood Drive, Danvers, MA 01923. Payment may also be made electronically through CCC Online at copyright.com. Other copying for republication, resale, advertising or promotion, or any form of systematic or multiple reproduction of any material in this book is prohibited except with permission in writing from the publisher. The CCC fee code is 0277-786X/08/ $\$ 18.00$.

Printed in the United States of America.

Paper Numbering: Proceedings of SPIE follow an e-First publication model, with papers published first online and then in print and on CD-ROM. Papers are published as they are submitted and meet publication criteria. A unique, consistent, permanent citation identifier (CID) number is assigned to each article at the time of the first publication. Utilization of CIDs allows articles to be fully citable as soon they are published online, and connects the same identifier to all online, print, and electronic versions of the publication. SPIE uses a six-digit CID article numbering system in which:

- The first four digits correspond to the SPIE volume number.

- The last two digits indicate publication order within the volume using a Base 36 numbering system employing both numerals and letters. These two-number sets start with 00, 01, 02, 03, 04, 05, 06, 07, 08 , 09, OA, OB ... 0Z, followed by 10-1Z, 20-2Z, etc.

The CID number appears on each page of the manuscript. The complete citation is used on the first page, and an abbreviated version on subsequent pages. Numbers in the index correspond to the last two digits of the six-digit CID number. 


\section{Contents}

ix Conference Committee
xi Introduction

\section{SESSION 1 STEGANOGRAPHY}

681902 Influence of embedding strategies on security of steganographic methods in the JPEG domain [6819-01]

J. Kodovský, J. Fridrich, Binghamton Univ., SUNY (USA)

681903 WLAN steganography revisited [6819-02]

C. Kraetzer, J. Dittmann, R. Merkel, Otto-von-Guericke-Univ. Magdeburg (Germany)

681904 Steganographic strategies for a square distortion function [6819-03]

A. D. Ker, Univ. of Oxford (United Kingdom)

681905 Revisiting weighted stego-image steganalysis [6819-04]

A. D. Ker, Univ. of Oxford (United Kingdom); R. Böhme, Technische Univ. Dresden

(Germany)

\section{SESSION 2 THEORETICAL METHODS}

681906 Security analysis of robust perceptual hashing [6819-05]

O. Koval, S. Voloshynovskiy, F. Beekhof, T. Pun, Univ. of Geneva (Switzerland)

681907 A low-rate fingerprinting code and its application to blind image fingerprinting [6819-06] J.-F. Jourdas, P. Moulin, Univ. of Illinois at Urbana-Champaign (USA)

681908 Improved lower bounds on embedding distortion in information hiding [6819-07]

Y. Kim, Z. Duric, D. Richards, George Mason Univ. (USA)

681909 Asymptotically optimum embedding strategy for one-bit watermarking under Gaussian attacks [6819-08]

P. Comesaña, Univ. of Vigo (Spain); N. Merhav, Technion-Israel Institute of Technology (Israel); M. Barni, Univ. of Siena (Italy)

$68190 \mathrm{~A}$ A high-rate fingerprinting code [6819-09]

J.-F. Jourdas, P. Moulin, Univ. of Illinois at Urbana-Champaign (USA)

\section{SESSION 3 PHYSICAL MEDIA}

6819 OB Analysis of physical unclonable identification based on reference list decoding [6819-10]

O. Koval, S. Voloshynovskiy, F. Beekhof, T. Pun, Univ. of Geneva (Switzerland) 
6819 OC Data embedding in hardcopy images via halftone-dot orientation modulation [6819-12]

O. Bulan, Univ. of Rochester (USA); V. Monga, Xerox Corp. (USA); G. Sharma, B. Oztan, Univ. of Rochester (USA)

6819 OD Secure surface identification codes [6819-13]

F. Beekhof, S. Voloshynovskiy, O. Koval, R. Villan, T. Pun, Univ. of Geneva (Switzerland)

\section{SESSION 4 FORENSICS}

6819 OE Camera identification from cropped and scaled images [6819-14]

M. Goljan, J. Fridrich, SUNY Binghamton (USA)

6819 OF On the detectability of local resampling in digital images [6819-15]

M. Kirchner, Technische Univ. Dresden (Germany)

6819 OG Scanner identification with extension to forgery detection [6819-16]

N. Khanna, G. T. C. Chiu, J. P. Allebach, E. J. Delp, Purdue Univ. (USA)

$6819 \mathrm{OH}$ Individuality evaluation for paper based artifact-metrics using transmitted light image [6819-17]

M. Yamakoshi, J. Tanaka, M. Furuie, M. Hirabayashi, National Printing Bureau (Japan);

T. Matsumoto, Yokohama National Univ. (Japan)

6819 Ol Camera identification from printed images [6819-18]

M. Goljan, J. Fridrich, J. Lukáš, SUNY Binghamton (USA)

\section{SESSION 5 AUDIO AND VIDEO I}

$68190 \mathrm{~J}$ Toward robust watermarking of scalable video [6819-19]

P. Meerwald, A. Uhl, Univ. of Salzburg (Austria)

6819 OK The video watermarking container: efficient real-time transaction watermarking [6819-20] P. Wolf, E. Haver, M. Steinebach, Fraunhofer SIT (Germany)

$6819 \mathrm{OL} \quad$ Robust audio hashing for audio authentication watermarking [6819-21]

S. Zmudzinski, M. Steinebach, Fraunhofer Institute for Secure Information Technology

(Germany)

\section{SESSION 6 BIOMETRICS}

6819 OM Comparison of compression algorithms' impact on iris recognition accuracy II: revisiting JPEG [6819-22]

S. Jenisch, S. Lukesch, A. Uhl, Univ. of Salzburg (Austria)

6819 ON Biometric hashing for handwriting: entropy-based feature selection and semantic fusion [6819-23]

T. Scheidat, C. Vielhaver, Univ. of Magdeburg (Germany) 
681900 Realization of correlation attack against the fuzzy vault scheme [6819-24]

A. Kholmatov, B. Yanikoglu, Sabanci Univ. (Turkey)

6819 OP Error exponent analysis of person identification based on fusion of dependent/independent modalities: multiple hypothesis testing case [6819-25]

O. Koval, S. Voloshynovskiy, R. Villan, T. Pun, Univ. of Geneva (Switzerland)

$68190 Q \quad$ Bridging biometrics and forensics [6819-26]

Y. Yan, L. A. Osadciw, Syracuse Univ. (USA)

6819 OR Security issues of Internet-based biometric authentication systems: risks of Man-in-theMiddle and BioPhishing on the example of BioWebAuth [6819-27]

C. Zeitz, T. Scheidat, J. Dittmann, C. Vielhaver, Univ. of Magdeburg (Germany);

E. González Agulla, E. Otero Muras, C. García Mateo, J. L. Alba Castro, Univ. of Vigo

(Spain)

\section{SESSION 7 APPLICATIONS}

6819 OS Anticollusion watermarking of 3D meshes by prewarping [6819-28]

F. Uccheddu, Univ. of Florence (Italy); C.-C. J. Kuo, Univ. of Southern California (USA);

M. Barni, Univ. of Siena (Italy)

6819 OT In-theater piracy: finding where the pirate was [6819-29]

B. Chupeau, A. Massoudi, F. Lefèbvre, Thomson R\&D France (France)

6819 OU A theoretical analysis of spatial/temporal modulation-based systems for prevention of illegal recordings in movie theaters [6819-30]

P. Bourdon, S. Thiebaud, D. Doyen, Thomson R\&D France (France)

6819 OV Toward DRM for 3D geometry data [6819-31]

M. Gschwandtner, A. Uhl, Univ. Salzburg (Austria)

\section{SESSION 8 AUDIO AND VIDEO II}

6819 OW Establishing target track history by digital watermarking [6819-32]

B. G. Mobasseri, P. Krishnamurthy, Villanova Univ. (USA)

6819 OX MPEG recompression detection based on block artifacts [6819-33]

W. Luo, Sun Yat-Sen Univ. (China) and Univ. of Maryland, College Park (USA); M. WU, Univ. of Maryland, College Park (USA); J. Huang, Sun Yat-Sen Univ. (China)

6819 OY Cover signal specific steganalysis: the impact of training on the example of two selected audio steganalysis approaches [6819-34]

C. Kraetzer, J. Dittmann, Otto-von-Guericke Univ. Magdeburg (Germany)

$68190 Z$ Evaluation of robustness and transparency of multiple audio watermark embedding [6819-35]

M. Steinebach, S. Zmudzinski, Fraunhofer Institute for Secure Information Technology (Germany) 
681910 Forensic watermarking and bit-rate conversion of partially encrypted AAC bitstreams [6819-36]

A. Lemma, S. Katzenbeisser, M. U. Celik, Philips Research Europe (Netherlands); S. Kirbiz, Istanbul Technical Univ. (Turkey)

\section{SESSION 9 STEGANALYSIS}

681911 Estimation of primary quantization matrix for steganalysis of double-compressed JPEG images [6819-37]

T. Pevný, J. Fridrich, Binghamton Univ., SUNY (USA)

681912 Textural features based universal steganalysis [6819-38]

B. Li, Sun Yat-Sen Univ. (China) and New Jersey Institute of Technology (USA); J. Huang, Sun Yat-Sen Univ. (China); Y. Q. Shi, New Jersey Institute of Technology (USA)

681913 Isotropy-based steganalysis in multiple least significant bits [6819-39]

X. YU, N. Babaguchi, Osaka Univ. (Japan); Y. Wang, Beihang Univ. (China)

$681914 \quad$ Nonparametric steganalysis of QIM data hiding using approximate entropy [6819-40] H. Malik, Univ. of Michigan-Dearborn (USA) and Stevens Institute of Technology (USA);

K. P. Subbalakshmi, R. Chandramouli, Stevens Institute of Technology (USA)

681915 Steganalysis-aware steganography: statistical indistinguishability despite high distortion [6819-41]

A. Orsdemir, H. O. Altun, G. Sharma, M. F. Bocko, Univ. of Rochester (USA)

681916 Steganographic capacity estimation for the statistical restoration framework [6819-42] A. Sarkar, Univ. of California, Santa Barbara (USA); K. Sullivan, Mayachitra, Inc. (USA);

B. S. Manjunath, Univ. of California, Santa Barbara (USA)

681917 Further study on YASS: steganography based on randomized embedding to resist blind steganalysis [6819-43]

A. Sarkar, Univ. of California, Santa Barbara (USA); K. Solanki, Mayachitra, Inc. (USA);

B. S. Manjunath, Univ. of California, Santa Barbara (USA)

\section{SESSION 10 EMBEDDING}

681918 Nested object watermarking: transparency and capacity evaluation [6819-44]

C. Vielhaver, M. Schott, C. Krätzer, J. Dittmann, Univ. of Magdeburg (Germany)

681919 Reduced embedding complexity using BP message passing for LDGM codes [6819-45]

P. Günther, D. Schönfeld, A. Winkler, Technische Univ. Dresden (Germany)

6819 1A A joint asymmetric watermarking and image encryption scheme [6819-46] G. Boato, V. Conotter, F. G. B. De Natale, Univ. of Trento (Italy); C. Fontanari, Politecnico di Torino (Italy)

6819 1B Robust digital image watermarking in curvelet domain [6819-47]

P. Tao, S. Dexter, A. M. Eskicioglu, City Univ. of New York (USA) 
6819 1C A joint digital watermarking and encryption method [6819-48]

M. Cancellaro, F. Battisti, M. Carli, Univ. degli Studi Roma Tre (Italy); G. Boato,

F. G. B. De Natale, Univ. of Trento (Italy); A. Neri, Univ. degli Studi Roma Tre (Italy)

6819 1D Embedding considering dependencies between pixels [6819-49]

E. Franz, Technische Univ. Dresden (Germany)

$68191 \mathrm{E}$ A reversible data hiding method for encrypted images [6819-50]

W. Puech, M. Chaumont, O. Strauss, Univ. of Montpellier II (France)

6819 IF Improved embedding efficiency and AWGN robustness for SS watermarks via pre-coding [6819-51]

H. O. Altun, O. Bulan, G. Sharma, M. F. Bocko, Univ. of Rochester (USA)

$68191 \mathrm{G}$ Perceptual hash based blind geometric synchronization of images for watermarking [6819-52]

B. Coskun, Polytechnic Univ. (USA); M. K. Mıhçak, Bogaziçi Univ. (Turkey)

Author Index 
Downloaded From: https://www.spiedigitallibrary.org/conference-proceedings-of-spie on 26 Apr 2023

Terms of Use: https://www.spiedigitallibrary.org/terms-of-use 


\title{
Conference Committee
}

\author{
Conference Chairs
}

Edward J. Delp III, Purdue University (USA)

Ping Wah Wong, IDzap LLC (USA)

Jana Dittmann, Otto-von-Guericke-Universität Magdeburg

(Germany)

Nasir D. Memon, Polytechnic University (USA)

Program Committee

Adnan M. Alattar, Digimarc Corporation (USA)

Oscar C. L. Au, Hong Kong University of Science and Technology (Hong Kong China)

Mauro Barni, Università degli Studi di Siena (Italy)

Jeffrey A. Bloom, THOMSON Corporate Research (USA)

Gordon W. Braudaway, IBM Corporation (USA)

Ee-Chien Chang, National University of Singapore (Singapore)

Jessica Fridrich, Binghamton University (USA)

Teddy Furon, IRISA (France)

Ton Kalker, Hewlett-Packard Company (USA)

Reginald L. Lagendijk, Technische Universiteit Delft (Netherlands)

Benoît Macq, Université Catholique de Louvain (Belgium)

Bangalore S. Manjunath, University of California, Santa Barbara (USA)

Pierre Moulin, University of Illinois at Urbana-Champaign (USA)

Fernando Pérez-González, Universidad de Vigo (Spain)

Reihaneh Safavi-Naini, University of Wollongong (Australia)

Bülent Sankur, Bogaziçi University (Turkey)

Gaurav Sharma, University of Rochester (USA)

Claus Vielhauer, Otto-von-Guericke-Universität Magdeburg (Germany)

Sviatoslav V. Voloshynovskiy, Université de Genève (Switzerland)

Min Wu, University of Maryland, College Park (USA)

\section{Session Chairs}

1 Steganography

Jessica Fridrich, Binghamton University (USA)

2 Theoretical Methods

Sviatoslav V. Voloshynovskiy, Université de Genève (Switzerland)

3 Physical Media

Gaurav Sharma, University of Rochester (USA) 
4 Forensics

Min Wu, University of Maryland, College Park (USA)

5 Audio and Video I

Adnan M. Alattar, Digimarc Corporation (USA)

6 Biometrics

Christian Kraetzer, Otto-von-Guericke-Universität Magdeburg (Germany)

$7 \quad$ Applications

Bijan G. Mobasseri, Villanova University (USA)

8 Audio and Video II

Jeffrey A. Bloom, THOMSON Corporate Research (USA)

9 Steganalysis

Chad D. Heitzenrater, Air Force Research Laboratory (USA)

10 Embedding

Vishal Monga, Xerox Corporation (USA) 


\section{Introduction}

Welcome to the Security, Steganography, and Watermarking of Multimedia Contents Conference! This is our 10th year of watermarking and multimedia security! More than 50 papers from more than 15 countries were presented at this year's conference.

The goal of the conference, as always, was to provide a forum for the discussion of issues in multimedia security. We had papers that addressed protecting audio, image, and video content, along with many interesting papers in cryptography and applications.

As we say every year, we have come a long way in protecting our "digital future," but we still have a lot of work to do. We would like to thank the Program Committee for their help in reviewing the papers and their advice on the final program.

We look forward to seeing you in 2009 in San Jose!

Edward J. Delp III

Ping Wah Wong Jana Dittmann Nasir D. Memon 
Downloaded From: https://www.spiedigitallibrary.org/conference-proceedings-of-spie on 26 Apr 2023

Terms of Use: https://www.spiedigitallibrary.org/terms-of-use 